\title{
Technique for Collecting Thrips for Use in Insecticide Efficacy Trials
}

\author{
Raymond A. Cloyd ${ }^{1}$ \\ University of Illinois, Department of Natural Resources and Environmental \\ Sciences, 228 Edward R. Madigan Laboratory, 1201 West Gregory Drive, \\ Urbana, IL 61801 \\ Daniel F. Warnock \\ University of Illinois, Department of Natural Resources and Environmental \\ Sciences, 1029 Plant Sciences Laboratory, 1201 South Dorner Drive, \\ Urbana, IL 61801
}

\section{Keith Holmes}

Rhone-Poulenc AG Company, P.O. Box 12014, 2 T.W. Alexander Drive, Research Triangle Park, NC 27709

Additional index words. collection device, Frankliniella occidentalis, artificial infestation, western flower thrips, insecticides

\begin{abstract}
An affordable device comprised of off-the-shelf parts, initially called the "Small Insect Aspirator" was developed to gently collect western flower thrips, Frankliniella occidentalis (Pergande), from a rearing colony for use in insecticide efficacy trials. This device allows for a designated number of thrips to be placed onto any experimental test plant. The device is a battery-motorized driven aspirator comprised of two pieces of copper tubing $(6.0 \mathrm{~mm}$ in diameter) attached to a copper housing, which contains a threaded plastic lid and glass vial $(20-\mathrm{mL})$. The aspirator is fully portable when attached to a battery-driven vacuum device, which allows researchers to efficiently collect thrips in outdoor field situations. When turned on, the vacuum gently pulls western flower thrips (adult and larval stages) through the copper tubing and deposits them into the collection vial. The vial is then detached and sealed with a threaded lid until the collected thrips are deposited onto experimental test plants.
\end{abstract}

Western flower thrips (WFT), Frankliniella occidentalis (Pergande), is a major greenhouse pest because it damages plants directly by feeding on foliage and flowers, and indirectly by vectoring viruses (Allen and Broadbent, 1986; DeAngelis et al., 1993; Robb, 1988). The most common management strategy to control thrips in commercial greenhouse production systems is the use of insecticides (Hudson et al., 1996). Insecticide efficacy trials may involve manually placing a designated number of thrips on plants (Robb et al., 1995) or relying on a natural population of thrips (Bennison et al., 1998; Fery and Schalk, 1991). Natural infestations may result in varying numbers of thrips among plants, among replications within an experiment, or among both.

The adult and larval stages of thrips move quickly or jump when disturbed, making them difficult to work with. A soft-bristled camel brush may be used to infest plants with live thrips (Cloyd and Sadof, 1998); this minimizes variability because an equal number of

\footnotetext{
Received for publication 9 May 2000. Accepted for publication 27 Dec. 2000. The cost of publishing this paper was defrayed in part by the payment of page charges. Under postal regulations, this paper therefore must be hereby marked advertisement solely to indicate this fact.

${ }^{1}$ To whom requests for reprints should be addressed. E-mail address: rcloyd@uiuc.edu
}

searchers must use methods that reduce experimental variation but are time and labor efficient. The development of a mass collection device for thrips would increase their efficiency.

\section{Materials and Methods}

A collection device, the "Small Insect Aspirator" (SIA) was designed to increase the efficiency and reduce problems associated with natural and manual infestation methods. In addition, a portable collection device to collect wild populations of thrips in field situations was desired. Although there are sucking and blowing type aspirators available (BioQuip Products, Gardena, Calif.) these are less efficient for field application because they require lung power, which results in inhaling dust and unwanted insect parts, and there is greater opportunity for the collection vials to fall off.

The SIA is a portable, battery-motorized, collection device (Mini-Vac, Glendale, Calif.) (Fig. 1) that may be attached to any lowpressure laboratory vacuum system with a short piece of rubber tubing. Two pieces of copper piping $(6.0 \mathrm{~mm}$ in diameter) are soldered to a copper housing that contains a lid and a vial (20-mL standard size) (Fig. 2). Insect screening $(135 u)$ is placed on the return section of pipe to prevent thrips from entering the housing (Fig. 2). Thrips from a colony or from plants in the field are vacuumed into the vial. When a designated number of thrips has been obtained, the vial is detached and sealed with a threaded lid. Multiple vials can be filled with a constant number of thrips in a short time. Thrips can be placed on test plants by removing the threaded lid and tapping the base of the vial. With the aspirator, an individual can collect and apply 25 thrips per plant to 50 plants in $1.5 \mathrm{~h}$, which is about twice as fast as can be done with a thrips can be placed on each plant, but is labor intensive and time-consuming compared with natural infestation. One person can usually inoculate 50 plants with 10 WFT adults or larvae in $3.5 \mathrm{~h}$ (Cloyd, personal observation). When infesting large numbers of plants, re-

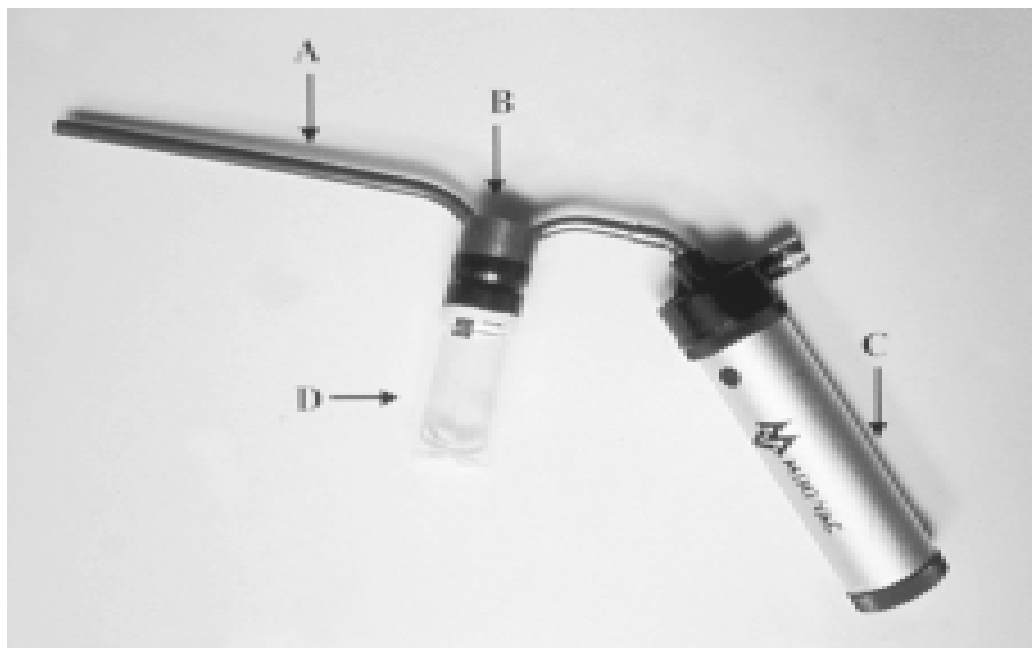

Fig. 1. Small Insect Aspirator components. Part $\mathbf{A}$ is comprised of a 20-cm section of 6-mm o.d. rigid copper pipe bent at a $90^{\circ}$ angle. Part $\mathbf{A}$ is inserted through a 7-mm hole drilled into Part $\mathbf{B}$, a 25-mm copper end cap glued to the lid of a 20-mL screw-top plastic vial, and soldered in place. A similar section of 6-mm rigid copper pipe connects Part $\mathbf{B}$ to Part $\mathbf{C}$, a battery operated mini-vacuum. Insects are collected into Part D, a 20- mL screw-top glass vial. When operating, the Mini-Vac pulls insects into the vial through the copper tubing (Part A). Insects are prevented from entering the Mini-Vac by screening placed over the end of the 6-mm pipe leading directly to the Mini-Vac (see Fig. 2). 


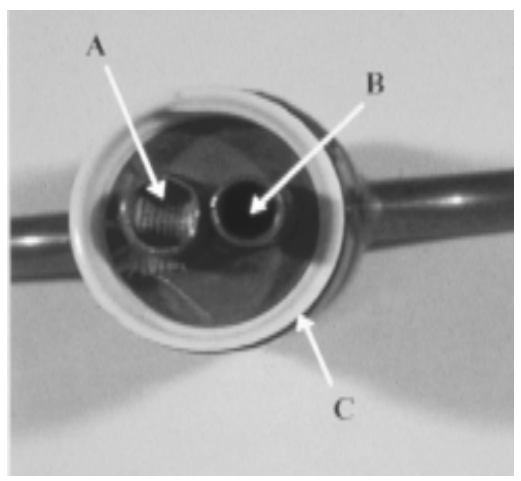

Fig. 2. Detail of internal portions of small insect aspirator. Arrow (A) is directed at screen (135 $u$ ) that prevents insects from being pulled into the Mini-Vac unit. Arrow (B) indicates the inlet for insects as they are pulled into the collection vial. Collection vials, $20 \mathrm{~mL}$ screwtop glass vials, are connected to the device by a plastic lid $(\mathbf{C})$, which is connected to a $25-\mathrm{mm}$ copper pipe end cap.

brush. This allows for many vials containing thrips to be used within a short time.

\section{Results and Discussion}

Reducing experimental variation is a goal of every researcher. Experiments involving insects may have high levels of variability because of the heterogeneous nature of insect populations. Beginning with a constant number of insects reduces confounding effects of plant preferences by insects in insecticide trials and host plant resistance studies, and can reduce the variability in the number of thrips recovered after application of insecticides.

Compared with natural infestation or manual (e.g., infestation with a brush) methods, use of the SIA facilitates collection of thrips and mitigates the problem of unequal infestation levels among plants and within experiments that are often associated with natural infestations. Based on visual observations, thrips are apparently unharmed, as they are mobile and population levels increase rapidly following infestation. In addition to insecticide efficacy trials, this device may be used for research on host plant resistance and biological control. Although initially designed for use with thrips, this device may be used for collecting other small insects such as adult greenhouse whitefly (Trialeurodes vaporariorum Westwood), shore fly (Scatella stagnalis Fallon), and leafminer (Liriomyza trifolii Burgess). Another advantage of the SIA is that the screwtype vial is less likely to fall off than are the snap-top vials traditionally used with commercially available insect aspirators. In addition, the aspirator costs $\approx \$ 25$ using off-theshelf parts, which is cheaper than commercially available portable aspirators, such as those offered by BioQuip Products (Gardena, Calif.).

In order for breeding programs designed to improve host plant resistance to be successful, several system components must be available, including segregating populations, mass-rearing methods for insects, appropriate infestation methods, and efficientevaluation methods (Fehr, 1987). For thrips researchers, several components, including mass-rearing methods (Steiner and Goodwin, 1998) and evaluation methods (Mollema et al., 1992) are currently available. However, infestation methods need to be improved. When combined with mass-rearing techniques for thrips, the SIA will allow researchers to increase the size of experiments on insecticide efficacy and host plant resistance. Because of its portability, it will also permit efficient collection of wild thrips in field situations.

\section{Literature Cited}

Allen, W.R. and A.B. Broadbent. 1986. Transmission of tomato spotted-wilt virus in Ontario greenhouses by Frankliniella occidentalis. Can J. Plant Pathol. 8:33-38.

Bennison, J.A., E.M. Pow, L.J. Wadhams, K.A. Maulden, L.R. Wardlow, and J.H. Buxton. 1998. Improving biological control of western flower thrips, Frankliniella occidentalis, on greenhouse ornamentals. In: Proc. 6 ${ }^{\text {th }}$ Intl. Symp. on Thysanoptera. Antalya, Turkey. (In Press.)

Cloyd, R.A. and C.S. Sadof. 1998. Flower quality, flower number, and western flower thrips density on transvaal daisy treated with granular insecticides. HortTechnology 8:567-570.

DeAngelis, J.D., D.M. Sether, and P.A. Rossignol. 1993. Survival, development, and reproduction in western flower thrips (Thysanoptera: Thripidae) exposed to impatiens necrotic spot virus. Environ. Entomol. 22:1308-1312.

Fehr, W.R. 1987. Principles of cultivar development. Vol. 1. Theory and technique. Macmillan, New York.

Fery, R.L., and J.M. Schalk. 1991. Resistance in pepper (Capsicum annuum L.) to western flower thrips [Frankliniella occidentalis (Pergande)]. HortScience 26:1073-1074.

Hudson, W.G., M.P. Garber, R.D. Oetting, R.F Mizell, A.R. Chase, and K. Bondari. 1996. Pest management in the United States greenhouse and nursery Industry. V. Insect and mite control. HortTechnology 6:216-221.

Mollema, C., F.R. van Dijken, K. Reinink, and R.C. Jansen. 1992. An automatic and accurate evaluation of thrips damage. Image-analysis: A new tool in breeding for resistance, p. 261-263. In S.B. Menken, J.H. Visser, and P. Harrewijn (eds.). Proc. $8^{\text {th }}$ Intl. Symp. on Insect-Plant Relationships. Kluwer Academic, Dordrecht, The Netherlands.

Robb, K.L. 1988. Analysis of Frankliniella occidentalis (Pergande) as a pest of floricultural crops in California greenhouses. PhD. Diss. Dept. of Entomology, Univ. Calif., Riverside.

Robb, K.L., J. Newman, J.K. Virz, and M.P. Parrella. 1995. Insecticide resistance in western flower thrips, p. 341-346. In: B.L. Parker, M. Skinner, and T. Lewis (eds.). Thrips biology and management. Plenum Press, New York.

Steiner, M.Y. and S. Goodwin. 1998. Methods for collecting and rearing thrips (Thysanoptera) and their natural enemies. Austral. J. Entomol. 37:101-106. 